\title{
Behavioral Aspects of ERP Implementation: A Conceptual Review
}

\author{
Prokreeti Mitra and Sasmita Mishra \\ KIIT School of Management, \\ KIIT University, Bhubaneswar, Odisha, India
}

\section{prokreetim@gmail.com sasmitamishra iitkgp@yahoo.co.in}

\begin{abstract}
Recently ERP implementation has seen increasing significance in different sectors. The research related to the implementation issues of ERP has also increased during the past decade. Particularly the behavioral aspects of ERP implementations have been researched in terms of identifying appropriate frameworks, critical success factors, perception and attitude of users and managers, the role of change agents, leadership, etc. This conceptual review summarizes some of the studies done on the above aspects and suggests further research areas. It is suggested that leadership competencies, learning attitude of the users, and organizational power dynamics can be potential areas of research in the context of ERP implementation.
\end{abstract}

Keywords: ERP Implementation, critical success factors, perception of users, leadership

\section{Introduction}

In the past decade there has been an extensive introduction of large scale information packages in all organizations, popularly known as ERP systems. Any ERP intervention in an organization has undergone a business process reengineering (BPR). With the implementation of BPR the organizations can seek strategic and innovative changes and achieve breakthrough performance (Sidikat \& Adeyemi, 2008). BPR is basically dependent on adoption of new methods or techniques which help to frame a better job, task and work modules and subsequently lead to the advent of a new work structure and procedure.

It is also noteworthy that process reengineering always has some effect on the behavioral aspect of an organization such as team conflict, decreased group cohesion, and decreased productivity. In general as these problems accentuate this ultimately leads to process failure. Consequently the company incurs loss for that. Hence, a substantial amount of research has been directed at understanding the behavioral processes in ERP implementation.

Material published as part of this publication, either on-line or in print, is copyrighted by the Informing Science Institute. Permission to make digital or paper copy of part or all of these works for personal or classroom use is granted without fee provided that the copies are not made or distributed for profit or commercial advantage AND that copies 1) bear this notice in full and 2) give the full citation on the first page. It is permissible to abstract these works so long as credit is given. To copy in all other cases or to republish or to post on a server or to redistribute to lists requires specific permission and payment of a fee. Contact Publish-

er@,InformingScience.org to request redistribution permission.

\section{Objective of the Paper}

The aim of this paper is to enumerate the critical behavioral factors influencing effective ERP implementation. 


\section{Scope of the Review}

For this review, only scholarly articles with the key word/phrase "ERP Implementation models", "User acceptance of ERP", "Critical success factors of ERP implementation" and "Leadership and ERP Implementation" have been considered. The search data bases were "Emerald", "EBSCO" and "Proquest". The articles referred were from 1999-2015.

Studies focusing on the successful implementation of ERP systems have tried to predict and validate the existing models as well as develop certain conceptual models for successful ERP implementation. At the same time, a huge number of research papers have focused on identifying the factors influencing successful implementation of ERP systems. Looking at the scope of this paper, we will only focus on the people/behavioral aspects of ERP implementation.

\section{Models Explaining Implementation of the ERP System}

The acceptance and adoption of technology is not so simple (Geels, 2005; Scott \& Vessey, 2002). Research reveals that $50 \%$ of the ERP implementations fail to meet the adopting organizations' expectations (Jasperson, Carter, \& Zmud, 2005; Seymour, Makanya, \& Berrange, 2007). There are also extreme cases of failure of ERP implementation (Scott \& Vessey, 2002). Therefore, many theories have been developed to explain the successful ERP implementation process. Some of the important theories are described below.

\section{System Dynamic Model}

The System Dynamic Model (Forrester, 1961), is a part of the Theory of Constraint. This provides a conceptual model that helps to gain insight into structures that create dynamic behavior in complex systems. The system pattern of behavior mainly results from the interaction of 3 core structures: 1) structure of the system, 2) time delays in feedback, 3) the extent to which a system flows and work is magnified through the feedback system. The system dynamic model can be illustrated as the diagram in Figure 1.

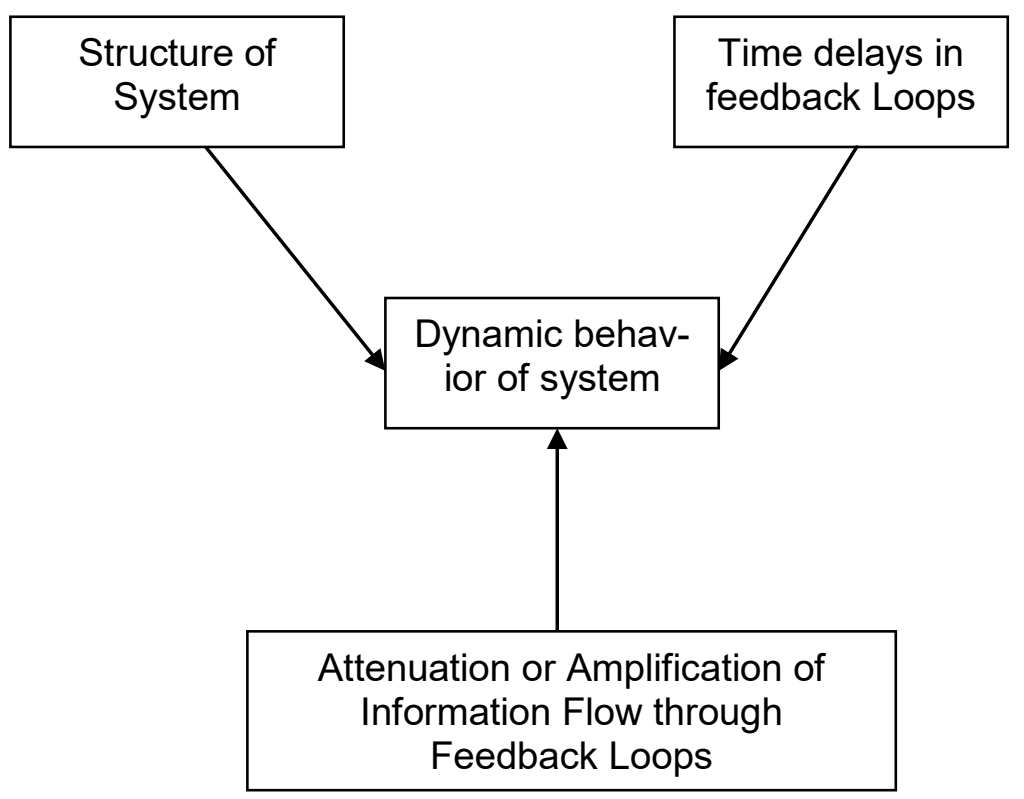

Figure 1. System Dynamic Model. Adapted from Reid \& Koljnen (1999)

Through this concept any manager gets an insight about the continuous improvement process, which is relative to their physical policy constraints in the production system. The limitation of 
the model was its inability to capture the complexity faced by any organization as it lacked a robust nature. Reid and Koljnen (1999) have discussed this model in the context of ERP implementation. However, application of this model in case of ERP implementation is very rare.

\section{Unified Theory of Acceptance and Use of Technology Model}

The Unified Theory of Acceptance and Use of Technology model (UTAUT) developed by Venkatesh, Morris, Davis, and Davis (2003) explains the end users' acceptance of ERP. This is a modified version of the Technology Adoption Model (TAM) as it considers the mandatory nature of ERP systems. As per this theory, when technological change happens, end users decide to adopt to change or resist it based on the evaluation features introduced in the IT infrastructure [in fact, the major cause of failure has been the resistance of end users (Aladwani, 2001)]. UTAUT postulates that the end user adoption of technology is based on four factors: performance expectancy, effort expectancy, social influence, and facilitating conditions to determine the usage of information technology. In a nutshell, this theory explains the factors influencing successful implementation of an ERP system and how several factors interact among themselves to influence acceptance of the system. The conceptual diagram of this model is given in Figure 2.

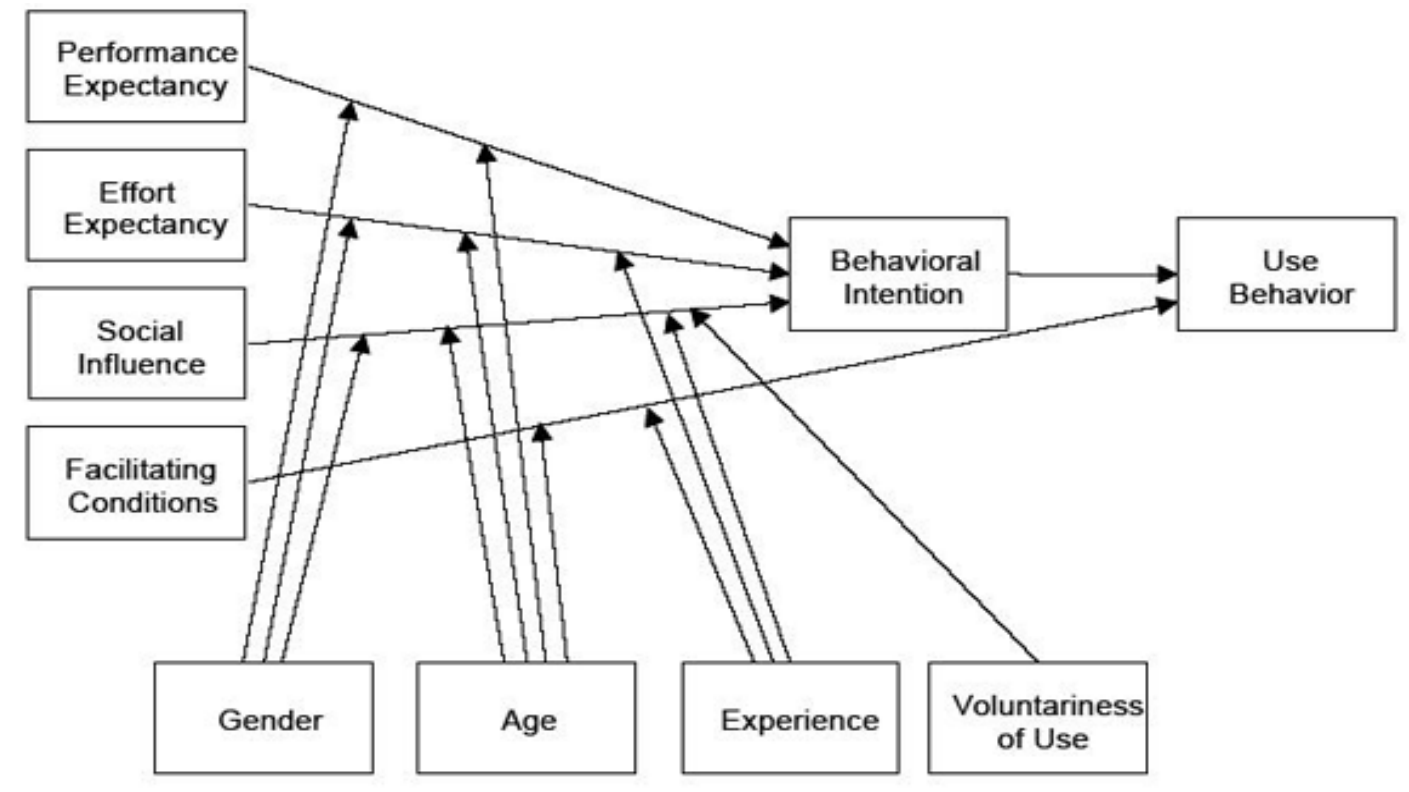

Figure 2. Unified Theory of Acceptance and Use of Technology model. Adapted from Venkatesh, Morris, Davis, and Davis (2003)

Many researchers have validated this theory in different cultural contexts (e.g., Chen \& Zeng, 2012; Coeurderoy, Guilmot, \& Vas, 2014). Some have also proposed adjusted or modified models of UTAUT (Keong, Ramayah, Kurnia, \& Chiun, 2012; Seymour et al., 2007).

\section{Ps Model of ERP Implementation}

Marnewick and Labuschagne (2005) proposed a conceptual model for enterprise resource planning where the complexity of an ERP system faced by any project manager and a non-technical member is described. Originally, the conceptual model was based on a 4 Ps model in marketing (McCarthy, 1960). The model asserts that if these four components are taken as a whole while implementing ERP, the end users of the software won't face any significant problem. Later this model was modified by replacing promotion and price with process and performance. The inter- 
linking of the components of the conceptual model with the 4 Ps marketing model can be illustrated as in Figure 3.

\begin{tabular}{|c|c|}
\hline 4 Ps & $\begin{array}{c}\text { ERP Conceptual } \\
\text { Model }\end{array}$ \\
\hline People & Customer mindset \\
\hline Product & Software \\
\hline Process & Change Management \\
\hline Performance & Process Flow \\
\hline
\end{tabular}

Figure 3. The 4 Ps model of ERP Implementation. Adapted from Marwenick and Labuschagne (2005)

\section{Punctuated Socio-technical Information Systems Change (PSIC)}

Lyytinen and Newman (2008) have proposed the Punctuated Socio-technical Information Systems Change (PSIC), which is used in organizations working at multiple levels such as work level, building level, and organization environment level. The model used a socio-technological event to measure the change which occurred. The critical views of the event focused on the sociotechnological gaps prevalent in the system. The socio- technological model can be illustrated as in Figure 4.

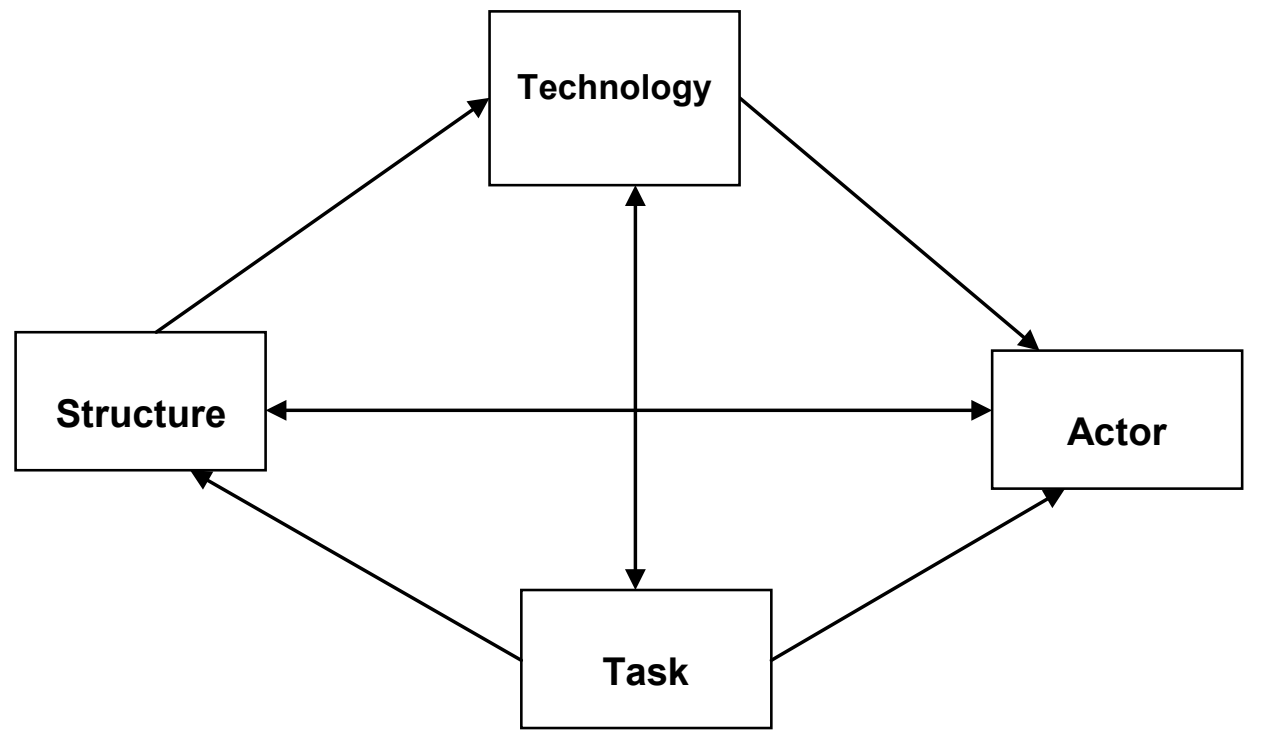

Figure 4. Socio Technological Model in respect to building IT system.

Adapted from Lyytinen and Newman (2008)

According to this model, changes in existing organizational routines and/or work processes can become critical incidents which in turn will affect the project implementation process.

\section{Lewis Actor Network Theory}

Lewis Actor Network Theory (ANT) (Latour, 1987; Lewis, 1998) is mainly used to study the dynamics of change. ANT (Callon, 1986; Latour, 1996; Law, 1992) attempts impartiality between all actors, whether human or non-human, and makes no distinction in approach between the so- 
cial, the natural, and the technological. According to Lewis (2007), ANT theory is a "grand theory" and provides "all-embracing" lenses through which a phenomenon can be understood in large scale, and this provides a framework for understanding the technological change. One of the proponents of this theory, Lowe (2000), described the steps that are involved in the change process: alignment, enrolment, and congealment. In the first step the "actants" (human and non-human) encounter the change process. In the second step all the "actants" progressively enroll themselves in new defined roles and build a stronger alliance of networks to support and diffuse the innovation. And finally, the change is consolidated and accepted as a part of life.

Wastell, Kawalek, and Newman (2003) have adopted the ANT theory to explore the dynamics of change in Government IT projects in Britain; however, they found the theory insufficient to explain the implementation process. They plead that further theories should focus on the potential resisting factors such as reason for organization crisis, recognition of the crisis, and perceived readiness of the organization to carry out change.

Close analysis of the aforesaid models reveals that behavioral aspects or the human/group behavior have an important place in all the models. It may be the customer mindset in the 4Ps model, dynamic behavior of the system in system dynamics model, the cultural norms/values existing in the organization, group/team processes in the organization, etc. Similarly, studies on the critical success factor of ERP implementation have also emphasized a number of behavioral factors such as employee training, team work, and user expectation. To gain an insight into this aspect of ERP implementation research, some of the important studies on critical success factors have been reviewed below.

\section{Factors Influencing Successful Implementation of ERP}

Most of the research on ERP has focused on identifying the critical success factors (Leung, Caswell, \& Kamath, 2005; Yang \& Tang, 2004). Some studies have also given some other perspective, looking at the complexities involved in ERP implementation. For example, Geels (2004) states that to go to any complex framework we have to open the existing one so that we can link up to the complex models.

An Indian study on the retail sector found that strategic, technological, people and project management are the factors which influence successful ERP implementation (Garg \& Garg, 2014). This study provides a holistic view of the implementation process, as data were collected from the project participants such as project sponsors, project managers, implementation consultants, and team members. Wickramasinghe and Gurawardena (2010) had collected data from 74 ERP implementation projects in Sri Lanka to identify the critical success factors of ERP implementation. Their study revealed that training and education, manager/user expectation, inter departmental cooperation, and effective communication were the key factors for successful ERP implementation. Several success factors have been classified by Hasibuan and Dantes (2012) as people, process \& organization and technology, where the people factor includes top management support, team work, user involvement, and use of consultants.

Taking excerpts from the models and the papers on critical success factors, we are enumerating below some of the factors related to people that are crucial for the successful implementation of ERP.

\section{Behavioral Aspects of ERP Implementation}

Human behavior in organizations has been conceptualized in three different levels: individual level, group level, and system level (Robbins, 2001). If we look at the behavioral aspects of ERP implementation in the lens of Robbin's Organizational Behavior model at the individual level, the issues are end user acceptance, attitude and perception of managers and users, technical profi- 
ciency of individuals, and teams. In group levels, the issues are team effectiveness, leadership, and organizational power dynamics. And at the system level, the researched factors are organizational culture and structure.

\section{End User Acceptance}

Any ERP implementation has a high technical success rate when it is accepted by the users. It is seen that technology, though considered to be robust, becomes unsuccessful if it is not adaptable by end users. In order to find a solution for this common issue, behavioral science researchers have vested much time and effort in it. Venkatesh, Thong, and Xu (2012) extended their study on the UTAUT theory of acceptance and use of technology and concluded that acceptance level of the end users varies across age, gender, and experience, which mainly occurs due to effects of hedonic motivation and price value. In fact, a great deal of research is directed at identifying the factors influencing end user acceptance (e.g., Venkatesh, Thung, \& Xu, 2012).

\section{Attitude of Managers and Users}

It is commonly said that behind any success one should have a positive attitude. Looking into today's scenario where companies have embraced change, it becomes a necessary factor for all employees to accept it and adapt themselves to that change. The adaptation process will only be possible if employees are having a positive attitude towards the system. Gobakhlo, Hong, Sabouri, and Zulfikli (2012) conducted an empirical study on an SME which adopted ERP software and found that there were many CSFs responsible for proper functioning of the software, including top management support. They assert that it is the sole responsibility of the top management, such as the CEO, to take innovative moves and show positive attitude to accept change. In their article they came up with a concept called Personal Innovativeness in IT (PIIT) which refers to "willingness of any individual to try out any new information technology". According to Amini and Safavi (2013), it is the end users' attitude towards the ERP system that influences their adoption of the software and their successful use of it. Al-Shamlan and Al- Mudiarigh (2011) also support this by saying that it is attitude which helps the members to cope with change. Considering the robust nature of technology it is the responsibility of the employees and employers to develop the right attitude and help each other to handle situations pertaining to change.

\section{Perception of Managers and Users}

Perceptions of key users and end users have been found to be an important factor influencing successful implementation of ERP (Amoako-Gyampah \& Salam, 2004; Nah, Zuckweiler, \& Lau, 2003). The factors that govern the perception of users are perceived ease of use, usefulness, perceived risk, etc. (Amoako-Gyampah \& Salam, 2004; Kwahk \& Lee, 2008). Amoaka-Gyamph (2004) found out that the managers had a more favorable perception about the benefits of technology than the end users. A cross-cultural study has found that Chinese managers and end users had less favorable perceptions towards ERP adoption than their US counterparts (Lin \& Rohm, 2009). It is clear that the perception of users is one of the aspects of readiness for change (Kwahk \& Lee, 2008).

\section{Technical Competency of Individuals and Groups}

Technical proficiency of the team members is required for any ERP implementation. Dezdar and Suleiman (2011) discuss that technological and business proficiency of team members is crucial for ERP project success. The ERP team is always cross-functional in nature and comprises of a mix of external consultants and internal staff. According to the nature of the team and the distribution of work proficiency, internal staffs should develop the necessary technical skills for system implementation. Aldammas and Al-Mudimigu (2011) also discuss the same cross functional 
nature of the ERP team and note that the internal team members should develop technical proficiency in order to work with the external consultants. They also found that it is the internal team members who are responsible for handling the implementation side of any project, so the technical proficiency is a must for the team and their members, because for any kind of issue their technical knowledge helps them in solving and smooth running of the project. Wang, Lin, Jiang, and Klein (2007) shift their focus to the knowledge transfer process happening in any implementation project. This is possible if the internal staff have the technical knowhow and can transfer the project duties to other team members. Thus technical training should be imparted to members if any gaps in the knowledge sharing process are noticed.

\section{Effectiveness of the Group and Team Process}

ERP implementation is always done by a project team. Hence, the success of a project depends on the attributes of the project team such as the team effectiveness and team leadership (Nah, Lau, \& Kuang, 2001; Rothenberger \& Srite, 2009; Stedman, 1999). Others such as Dean, Deokar, and Bush (2006) discuss how collaborative intervention can improve group efficiency and effectiveness for many group processes. They assert that many tasks in an organization can benefit from collaborative involvement. It is also seen to be successful when projects support collaborative investment and when there is enough budgeted to design and implement it. Similarly, Yang and Tang (2004) focus on the Information System (IS) development and how the teams behave during that development. Their empirical study found that group cohesion was a factor which was related with the overall performance of the team.

\section{Leadership / Change Agent}

The role of leadership in technical project implementation has drawn the attention of many researchers (Jiang, Klein, \& Chenoun-Gee 2001; Thite, 2000; Wang, Chou, \& Jiang, 2005). They have found leadership to be the most important factor in ERP implementation. Leaders act as the change agents, and hence their skills (Tasmin, Saufi, \& Rusuli, 2010) and leadership style contribute a lot to the implementation of any IT structure. For example, Leung, Caswell, \& Kamath (2005) suggest that persons with highly equipped BPR skills and KMS need to be hired and replace the persons working on an ad-hoc basis. This will help the system run without problems. However, studies also report that the external agents such as consultants are also greatly responsible for success of ERP implementation (Doom, Milis, Poelmans, \& Bloemen, 2010).

\section{Leadership traits}

Studies have also been done to find out some interesting characteristics of change agents. McMaster, Wastell, and Henriksen (2005) have tried to understand the role of corporate jester in the change management process. They opine that there are many roles and attributes played by a change agent. The change agents with wit and humor can contribute a lot in the change process as humor in the workplace has been seen as an empowerment tool. Similarly, Wang, Chou, and Jiang (2005) found a positive relationship between charismatic leadership and successful ERP implementation.

Vertical leadership. Vertical or hierarchical leadership (Morgeson, DeRue, \& Karam, 2010; Yukl, 2009) may be viewed as formal, external or internal, leadership behavior. Hence, studies have highlighted the empowerment of middle-management (Dennis, Carte, \& Kelly, 2003) and favorable attitude of top management (Dezdar \& Sulaiman, 2011) for successful implementation of ERP. It is the strategic and tactical action of top management that boosts a culture conducive for ERP implementation (Ke \& Wei, 2005). Managers need to focus more on innovation and creativity of the workplace to improve attitudes of employees (Saemani, Nourbaksh, \& Sepasi, 
2015). This study also reports that the moral intelligence level of managers is the key to success of the ERP implementation.

\section{Leadership styles}

Transformational leadership. Researchers have tried to identify many leadership styles instrumental in the successful implementation of ERP. Elkhani, Soltani, and Ahmad (2014) opine that transformational leadership style can be the best leadership style to drive the ERP implementation process. Similarly, Al- Omari, and Hung (2012) have found that transformational leaders with high emotional intelligence heighten the organizational innovation process. Further, they assert that the present business scenario is highly volatile given the difficulty in forecasting the supply and demand fluctuations, thus organizations require leaders who can streamline the process transience and bring system stability in achieving sustainable growth.

A study conducted in a manufacturing company reveals that transformational leadership will only help to transform the production system into a flexible one by removing all the complexity in the process (Birasnav, 2014). Such leaders ensure that quality is maintained in all the levels of the production process.

Transactional leadership. Unlike transformational leadership, a transactional leadership style has been found to be ineffective in influencing the perceived usefulness of the technology (Shepers, Wetzels, \& Ruyter, 2005). The role of transactional and transformational leadership has been discussed in the context of organizational change (Burns, 1978). While transactional leadership rewards employees for adapting to new cultures, transformational leadership inspires the subordinates to assume change. Shao, Feng, and $\mathrm{Hu}$, (2011) opine that transactional leadership is more effective in the implementation phase, whereas mixed leadership can be found effective in the assimilation and extension phases. According to them, effective implementation of ERP requires a perfect blend of strong visionary skill as well as managerial skill. Looking at this dichotomy, studies have used a Multi-factor Leadership Questionnaire (Bass \& Avolio, 1997) to identify leadership style and give training to develop a perfect blend of styles among managers.

Other leadership concepts (e-leaders and shared leadership). Since ERP implementation requires a team effort and organization wide acceptance, shared leadership has been proposed to be effective in such context (Hoch \& Dulebohn, 2013). Organizations operating globally have virtual teams and in such context ERP implementation requires a different kind of leadership. Such leaders have been coined as e-leaders (Lilian, 2014). Little research has been done on these aspects.

\section{Organizational Power Dynamics}

End users are not the only responsible factor for the successful running of any ERP software. The culture of the organization also influences concurrently the successful implementation of ERP. When we talk about organizational culture, the first thing we think of is organizational politics. Both could be termed as intertwined terms. Many studies have been conducted particularly on political issues which said that they have a very negative impact on the innovative progress of any organization and have often led to unplanned events in the environment. Hajri, Xu, Nuvangi, and Sedera (2014) said that political issues within a team impedes any change process. Chiang (2013) in his study explicitly talks about organizational change and the negative impact of politics on organizational learning processes. So, employers as well as employees should be very cautious about political issues persisting in an organization and steps should be taken to eradicate them so that they do not hamper the day-to-day process. 


\section{Organizational Culture}

Any discussion of behavior is incomplete without referring to organizational culture. Successful ERP implementation has been found to be greatly influenced by culture (Annamalai \& Ramayah, 2013; Boersma \& Kingma, 2005; Rabaa'i, 2009). ERP implementation studies emphasizing culture have adopted two approaches: the life world and the system approach (Tennekes, 1995). Studies adopting the system approach emphasized the coordination of people and divisions, hierarchical power relations, etc. Contrarily, studies adopting the life world approach have tried to understand the motives and identities of the actors (Alvarez \& Urla, 2002; Czamiawska, 1998).

Sometimes national culture has been found to be instrumental in ERP implementation (Motwani, Subramanian, \& Gopalakrishana, 2005; Tarafdar \& Roy, 2003; Zhang, Lee, Zhang, \& Banerjee, 2003). These studies argued that national cultures influence their work culture, and hence the acceptance of ERP and implementation of ERP is influenced accordingly. Studies have also tried to establish the role of culture by comparing public sector and private sector companies (Rabaa'i, 2009).

Organizational culture has also been found out to be a moderator influencing the relationship between critical success factors and ERP implementation success (Annamalai \& Ramayah, 2013).

\section{Future Research Direction and Conclusion}

Technology may be the enabler but it is ultimately the people within the organization who have to implement the ERP, use it, and take steps to maintain it. Hence, behavioral aspects of ERP implementation will always be a crucial factor determining success of ERPs. Therefore, understanding and exploring the people issues is essential. Critical analysis of the afore-mentioned literature has uncovered the following research gaps.

Studies have been conducted on different national and organizational cultural contexts to explore how people from different cultures embrace ERP. Still more studies are required to gain insight into the behavioral processes.

It is leadership that leads to enhanced capability of the subordinates to endure the challenges posed by the change process. Further research can be conducted to identify the proper blend of knowledge, skills, and ability required by leaders for successful implementation of ERP. Some emphasis has already been put on this direction, stating that leaders should have problem solving skills and employee friendly communication (Ash \& Burn, 2003) as well as sufficient strength and authority over all stakeholders (Sarker \& Lee, 2003) for effective implementation of ERP.

Moreover, ERP implementation in organizations can be analogous to planned and revolutionary change. Fugate (2012) suggests that such changes require leaders to adopt a balanced approach of leadership involving vision and guidance on the one hand and planning and execution on the other hand. In the same line Yukl and Lepsinger (2005) suggest a flexible leadership model for effective implementation of change. By flexible leadership they also hint at a perfect blend of leadership and management behavior. They have identified three indicators of flexible leadership: (1) efficiency and reliability, (2) innovation and adaptation, and (3) human resources and relations. Further research can also be done in this area to see the effectiveness of such leadership style in different ERP implementation projects.

A great deal of research, particularly based on UTAUT theory, focuses on attitude and perception of end users in success of the ERP implementation (Gobakhloo, Hong, Sabouri, \& Zulkifli, 2012; Nah, Tan, \& Teh, 2004). However, use of ERP systems also requires the users to learn new technology, remain open to change, and remain aware of technological developments. Hence, the measure of the attitude of the users towards learning new technology, openness to change, and innovation can be a potential predictor of ERP adoption. Although research has focused on the 
training of the users, and attitude of the users in general, the above dimensions of user attitudes have not specifically been measured.

Similarly, the role of organizational power dynamics, which has been studied a lot in the area of change management, can be a researchable factor influencing ERP implementation. This factor has received much less attention in ERP implementation literature. Hence, developing an appropriate measure to capture this factor and establishing an empirical relationship with ERP adoption can give a new dimension to ERP implementation researchers and practitioners.

Studies have focused on the team competency and team effectiveness. Looking at the rate of attrition and job hopping of technically sound ERP implementation team members, creating a team successor has become a practical issue and need for implementing organizations. Hence, research can be directed at this issue.

\section{References}

Al-Omari, M. A. M., \& Hung, D. K. M. (2012). Transformational leadership and organizational innovation: The moderating effect of emotional intelligence. International Business Management, 6(3), 308-316.

Aladwani, A. M. (2001). Change management strategies for successful ERP implementation. Business Process Management Journal, 7(3), 266-275.

Aldammas, A., \& AI-Mudimigh, A. S. (2011). Critical success and failure factors of ERP implementations: Two cases from kingdom of Saudi Arabia. Journal of Theoretical and Applied Information Technology, 28(2), 73-82.

Al-Shamlan, H. M., \& Al-Mudiarigh, A. S. (2011). The change management strategies and processes for successful ERP implementation: A case study of MADAR. IJCSI: International Journal of Computer Science Issues, 8(2), 399-407.

Alvarez, R., \& Urla, J. (2002). Tell me a good story: Using narrative analysis to examine information requirements interviews during an ERP implementation. ACM SIGMIS Database, 33(1), 38-52.

Amini, M., \& Safavi, N. S. (2013). Review paper: Critical success factors for ERP implementation. International Journal of Information Systems, 5(6), 1-23.

Amoako-Gyampah, K. (2004). ERP implementation factors: A comparison of managerial and end user perspectives. Business Process Management Journal, 10(2), 171-183.

Amoako-Gyampah, K. \& Salam, A. F. (2004). An extension of the technology acceptance model in an ERP implementation environment. Information \& Management, 41, 731-745.

Annamamlai, C. \& Ramayah, T. (2013). Does the organizational culture act as the moderator in Indian enterprise resource planning (ERP) projects? Journal of Manufacturing Technology Management, 24(4), 555-587.

Ash, C. G., \& Burn, J. M. (2003). A strategic framework for the management of ERP enabled e-business change. European Journal of Operational Research, 146(2), 374-386.

Bass, B. M., \& Avolio, B. J. (1997). Full range leadership development: Manual for the Multifactor Leadership Questionnaire. Palo Alto, CA: Mind Garden.

Biransav, M. (2014). Relationship between transformational leadership behaviors and manufacturing strategy. International Journal of Organizational Analysis, 22(2), 205-223.

Boersma, K., \& Kingma, S. (2005). Developing a cultural perspective on ERP. Business Process Management Journal, 11(2), 123-136.

Burns, J. M. (1978). Leadership. New York: Harper \& Row. 
Callon, M. (1986). Some elements of a sociology of translation: Domestication of the scallops and the fishermen of St Brieuc Bay. In J. Law (Ed.), Power, action and belief: A new sociology of knowledge (pp. 196-233). London: Routledge and Kegan Paul.

Chen, B., \& Zeng, Z. (2012). ERP usage in practice: Understanding end-users' acceptance of ERP systems in Chinese large companies by applying UTAUT model (unpublished Bachelor's thesis). Jonkoping International Business School, Jonkoping University, Jönköping, Sweden.

Chiang, M-H. (2013). Organizational change in ERP implementation: A dialectical perspective. Journal of Global Business Management, 9(1), 175-185.

Coeurderoy, R, Guilmot, N., \& Vas, A. (2014). Explaining the factors affecting technological change adoption. Management Decision, 52(6), 1082-1110.

Czarniawska, B. (1998). A narrative approach to organization studies. Thousand Oaks, CA: Sage Publications.

Dean, D. L., Deokar, A., \& Bush, R. T. (2006). Making the collaboration engineering investment decision. Proceedings of the 39th Annual Hawaii International Conference on System Sciences.

Dennis, R. A., Carte, T. A., \& Kelly, G. G. (2003). Breaking the rules: Success and failure in groupware supported business process reengineering. Decision Support System, 36(1), 31-47.

Dezdar, S., \& Sulaiman, A. (2011). The influence of organizational factors on successful ERP implementation. Management Decision, 49(6), 911-926.

Doom, C., Milis, K., Poumans, S., \& Bloemen, E. (2010). Critical success factors for ERP implementation in Belgian SME. Journal of Enterprise Information Management, 23(3), 378-406.

Elkhani, N., Soltani, S., \& Ahmed, M. N. (2014). The effects of transformational leadership and ERP system and self-efficacy on ERP system usage. Journal of Enterprise Information Management, 27(6), 759-785.

Forrester, J. (1961). Industrial dynamics. Cambridge, MA: MIT Press.

Fugate, M. (2012). Impact of leadership management and HRM on employee reactions to organizational change. Personnel and Human Resource Management, 31,181-212.

Garg, P., \& Garg, A. (2014). Factors influencing ERP implementation in retail sector: An empirical study from India. Journal of Enterprise Information Management, 27(4), 424-448.

Geels, F. W. (2004). From sectoral systems of innovation to socio technical systems: Insights about dynamics and change from sociology and institutional theory. Research Policy, 33(6-7), 897-920.

Geels, F. W. (2005). The dynamics of transition in socio technical systems: A multi level analysis of transition pathway from horse drawn carriages to automobiles. Technology Analysis and Strategic Management, 17(4), 445-476.

Gobakhloo, M., Hong,T. S., Sabouri, M. S., \& Zulfikli, N. (2012). Strategies for successful information technology adoption in small medium sized enterprises. Information Journal, 3, 36-67.

Hajri, Z. A., Xu, W., Nuvangi, S. M., \& Sedera, D. (2014). Individual Innovative Use of ERP Systems. Paper presented in Second European Conference on Information Sciences. Accessed on 15.07.2015 at http://ecis2014.eu/E-poster/files/0459-file1.pdf

Hasibuan, Z., \& Dantes, G. (2012). Priority of key success factors (KSFs) on enterprise resource planning (ERP) system implementation life cycle. Journal of Enterprise Resource Planning Studies, 2012, 115 .

Hoch, J. E., \& Dulebohn, J. H. (2013). Shared leadership in enterprise resource planning and human resource management system implementation. Human Resource Management Review, 23, 114-125.

Jasperson, J., Carter, P. F., \& Zmud, R. W. (2005). A comprehensive conceptualization of the post-adoptive behaviors associated with IT-enabled work systems. MIS Quarterly, 29, 525-557. 
Jiang, J. J., Klein, G., \& Chenoun-Gee, H. (2001). The relative influence of IS project implementation policies and project leadership on eventual outcomes. Project Management Journal, 32(3), 49-55.

Ke, W., \& Wei, K. K. (2005). Organizational culture and leadership in ERP implementation. Decision Support Systems, 45(2), 208-218.

Keong, M. L., Ramayah, T., Kurnia, S., \& Chiun, L. M. (2012). Explaining intention to use an enterprise resource planning (ERP) system: An extension of the UTAUT model. Business Strategy Series, 13(4), $173-180$.

Kwahk, K-Y., \& Lee, J-N. (2008). The role of readiness for change in ERP implementation: Theoretical bases and empirical validation. Information \& Management, 45, 474-481.

Latour, B. (1987). Science in action. Cambridge, Massachusetts: Harvard University Press.

Latour, B. (1996) Aramis or the love of technology. Cambridge, Mass: Harvard University Press.

Law, J. (1992). Notes on the theory of actor-network. Ordering, strategy and heterogeneity. System Practice, 5(4), 379-393.

Leung, Y. T., Caswell, N., \& Kamath, M. (2005). The case for business process engineer. Published in IBM research division.

Lewis, D. (1998). Partnership as process: Building an institutional ethnography of an inter-agency aquaculture project in Bangladesh. In D. Mosse, J. Farrington, \& A. Rew (Eds.), Development as process: Concepts and methods of working with complexity (pp. 99-114), London: Routledge.

Lewis, P. J. (2007). Using ANT ideas in the managing of systemic action. Management Science Working Paper Series. Lancaster University: The Department of Management Science. Accessed on February 23, 2012 from http://www.research.lancs.ac.uk/portal/services/downloadRegister/588867/Document.pdf

Lilian, S. C. (2014). Virtual teams: Opportunities and challenges for e-leaders. Social and Behavioral Sciences, 110, 1251-1261.

Lin, F., \& Rohm, C. E. T. (2009). Managers' and end-users' concerns on innovation implementation: A case of an ERP implementation in China. Business Process Management Journal, 15(4), 527-547.

Lowe, A. D. (2000). The construction of a network at Health Waikato: The 'towards clinical budgeting' project. Accounting Auditing and Accountability Journal, 13(1), 84-114.

Lyytinen, K., \& Newman, M. (2008). Explaining information systems change: A punctuated socio technological change model. European Journal of Information System, 17, 589-613.

Marnewick, C., \& Labuschagne, L. (2005). A conceptual model for enterprise resource planning (ERP). Information Management and Computer Security, 13(2), 144-155.

McCarthy, E. J. (1960). Basic marketing: A managerial approach. Homewood, IL: Richard D. Irwin.

McMaster, T., Wastell, D., \& Henriksen, H. Z. (2005). Fooling around: The corporate jester as an effective change agent for technological innovation? Proceedings of the IFIP TC8 WG 8.6 conference, Atlanta, USA.

Morgeson, F. P., DeRue, D. S., \& Karam, E. P. (2010). Leadership in teams: A functional approach to understanding leadership structures and processes. Journal of Management, 36, 5-39.

Motwani, J., Subramanian, R., \& Gopalakrishna, P. (2005). Critical factors for successful ERP implementation: Exploratory findings from four case studies. Computers in Industry, 56, 529-544.

Nah, F. F-H., Lau, J. L. S., \& Kuang, J. (2001). Critical factors for successful implementation of enterprise systems. Business Process Management Journal, 7, 285-296.

Nah, F.F-H, Tan X., \& Teh, S. H. (2004). An empirical investigation on end -user's acceptance of enterprise systems. Information Resources Management Journal, 17(3), 32-53. 
Nah, F. F-H., Zuckweiler, K. M., \& Lau, J.L.S. (2003). ERP implementation: Chief information officers' perceptions of critical success factors. International Journal of Human Computer Interaction, 16, 5-22.

Rabaa'i, A. (2009). The impact of organizational culture on ERP systems implementation: Lessons from Jordan. In Proceedings of the Pacific Asia Conference on Information Systems (PACIS) 2009.

Reid, R. A., \& Koljnen, E. L. (1999). Validating a manufacturing paradigm: System dynamics model approach. International Journal of Group Psychology, July, 292-304.

Robbins, S. P. (2001). Organizational behavior (9th ed.). Upper Saddle River, NJ: Prentice-Hall.

Rothenberger, M., \& Srite, M. (2009). An investigation of customization in ERP system implementations. IEEE Transactions on Engineering Management, 56, 663-676.

Saemani, H., Nourbaksh, P., \& Sepasi, H. (2015). Innovative organizational climate, moral intelligence and attitude towards change. Management Research Report, 3(2), 527-535.

Sarker, S., \& Lee, A. S. (2003). Using a case study to test the role of three key social enablers in ERP implementation. Information \& Management, 40, 813-829.

Shepers, J., Wetzels, M., \& Ruyter, K. D. (2005). Leadership styles in technology acceptance: Do followers practice what leaders preach? Managing Service Quality, 15(6), 496-508.

Scott, J. E., \& Vessey, I. (2002). Managing risks in enterprise systems implementations. Communication of the $A C M, 45(4), 74-81$.

Seymour, L., Makanya, W., \& Berrange, S. (2007). End-users' acceptance of enterprise resource planning systems: An investigation of antecedents. Proceedings of the 6th Annual ISOneWorld Conference, Las Vegas, NV. Available at https://www.researchgate.net/profile/Lisa_Seymour2/publication/237133949_End-

Us-

ers'_Acceptance_of Enterprise_Resource_Planning_Systems_An_Investigation_of_Antecedents/links/ $\underline{549945600 \mathrm{cf} 21 \mathrm{eb} 3 \mathrm{df} 5 \mathrm{f} 772 \mathrm{~d} . \mathrm{pdf}}$

Shao, Z., Feng, Y., \& Hu, L. (2011). How leadership styles impact enterprise systems success throughout the lifecycle: A theoretical exploration. Working paper on information system, 11(135).

Sidikat, A., \& Adeyemi, A. M. (2008). Impact assessment of business process reengineering on organizational performance of First Bank Nigeria. European Journal of Social Sciences, 7(1), 115-125.

Stedman, C. (1999, November 1). Failed ERP gamble haunts Hershey. Computerworld, 33(44), 1, 89. Available at http://us.badm.washington.edu/sikkema/IS300/InClassCases/failed\%20ERP\%20haunts\%20hershey.pdf

Tarafdar, M., \& Roy, R. K. (2003). Analyzing the adoption of enterprise resource planning systems in Indian organizations: A process framework. Journal of Global Information Technology Management, 6 , 31.

Tasmin, R., Saufi, M. \& Rusuli, C. (2010). Applicability of socio technical model (STM) in working system of modern organizations. Journal of Techno-Social, 2(2), 62-79.

Tennekes, J. (1995). Organisatiecultuur. Een antropologische visie, Leuven/Apeldoorn: Garant

Thite, M. (2000). Leadership styles in information technology projects. International Journal of Project Management, 18, 235-241.

Venkatesh, V., Thong, Y. L. V. J., \& Xu, X. (2012). Consumer acceptance and use of information technology: Extending the unified theory of acceptance and use of technology, MIS Quarterly, 36(1), 157-178.

Venkatesh, V., Morris, M. G., Davis, G. B., \& Davis, F.,D. (2003). User acceptance of information technology: Towards a unified view. MIS Quarterly, 27(3), 425-478.

Wang, E. T. G., Chia-Lin Lin, C., Jiang, J. J., \& Klein, G., (2007). Improving enterprise resource planning (ERP) fit to organizational process through knowledge transfer. International Journal of Information Management 27, 200-212. 
Wang, E., Chou, H-W, \& Jiang, J. (2005). The impacts of charismatic leadership style on team cohesiveness and overall performance during ERP implementation. International Journal of Project Management, 23, 173-180.

Wastell, D., Kawalek, P., \& Newman, M. (2003). Plus ca change: Defensive translations and resistance to IT-enabled change in local government. Proceedings of European Conference of Information Systems, 2003, Naples, Italy.

Wickramasinghe, V., \& Gurawardena, V. (2010). Critical elements that discriminate between successful and unsuccessful ERP implementation in Sri Lanka. Journal of Enterprise Information Management, 23(4), 466-485.

Yang, L. H., \& Tang, J. H. (2004). Team structure and team performance in IS development: A social network perspective. Information and Management Journal, 41(3), 335-349.

Yukl, G. (2009). Leading organizational learning; Reflections on theory and research. The Leadership Quarterly, 20, 49-53.

Yukl, G., \& Lepsinger, R. (2005). Why integrating the leading and managing roles is essential for organizational effectiveness. Organizational Dynamics, 34(4), 361-375.

Zhang, L., Lee, M. K. O., Zhang, Z., \& Banerjee, P. (2003). Critical success factors of enterprise resource planning systems implementation success in China. Proceedings of the $36^{\text {th }}$ Hawaii International Conference on System Sciences (HICSS '03), IEEE Computer Society, Washington, DC, pp. 1-10.

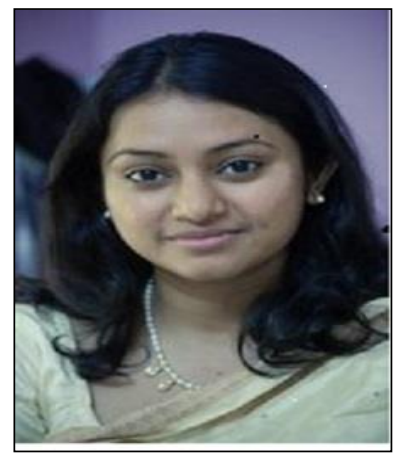

\section{Biographies}

Ms. Prokreeti Mitra is currently pursuing her doctoral course in KIIT School of Management, KIIT University, Bhubaneswar. She is an MBA graduate from ICFAI University in 2007. She has some enriched experience in the domain of HRM which included primarily recruitment, employee engagement, time management, on boarding and exit formalities, induction training, leave management, performance appraisal, and also administrative roles. Meanwhile she completed my SAP certification on HCM module and was a trainer in institutes likes Atos, JKT.

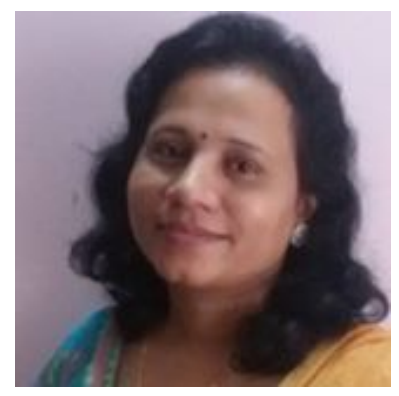

Dr. Sasmita Mishra is currently an Assistant Professor in the area of Organizational Behavior and Human Resource Management. Her areas of research interest are Social Psychology, Community Psychology, Environmental Psychology and Organizational Behavior. She has around ten years of experience in teaching and research. 